ARTIKEL PENELITIAN

\title{
Strategi Regulasi Emosi terhadap Stres Akademis selama Menjalani Kuliah Daring di Masa Pandemi Covid-19
}

\author{
ARINI RACHMAWATI \& IKA YUNIAR CAHYANTI* \\ Departemen Psikologi Klinis dan Kesehatan Mental, Fakultas Psikologi Universitas Airlangga
}

\begin{abstract}
ABSTRAK
Perkuliahan daring akibat adanya pandemi Covid-19 berpotensi memicu stres akademis pada mahasiswa. Penggunaan strategi regulasi emosi yang tepat dianggap dapat membantu mahasiswa untuk mereduksi stres akademis. Peneliti ingin mengetahui lebih lanjut mengenai hubungan antara strategi regulasi emosi dengan stres akademis pada mahasiswa. Penelitian ini dilakukan kepada 285 mahasiswa Universitas Airlangga (237 perempuan dan 48 laki-laki) dengan menggunakan kuesioner. Peneliti menggunakan Student-life Stress Inventory untuk mengukur stres akademis dan Emotion Regulation Questionnaire untuk mengukur strategi regulasi emosi. Hasil penelitian menunjukkan bahwa $p=0,477$ untuk cognitive reappraisal dengan stres akademis dan $p=0,249$ untuk expressive suppression dengan stres akademis. Variabel dapat dikatakan saling berhubungan apabila nilai $p<0,05$.Sehingga dapat disimpulkan bahwa tidak terdapat hubungan yang signifikan antara strategi regulasi emosi dengan stres akademis pada mahasiswa selama menjalani kuliah daring. Hal tersebut menunjukkan bahwa hipotesis penelitian ini ditolak.
\end{abstract}

Kata kunci: kuliah daring, strategi regulasi emosi, stres akademis

\begin{abstract}
Online lectures due to the Covid-19 pandemic potentially trigger academic stress on students. The use of emotion regulation strategies may help students to reduce it. This study aims to see the relationship between emotional regulation strategies with academic stress on students during their online lectures. This research was conducted on 285 students at Universitas Airlangga (237 women and 48 men) performed using a questionnaire. This research used Student-life Stress Inventory to measure academic stress and Emotion Regulation Questionnaire to measure emotion regulation strategies. The results showed that $p=0,477$ for cognitive reappraisal with academic stress and $p=0,249$ for expressive stress with academic stress. Therefore, it can be concluded that there is no significant relationship between emotion regulation strategies and academic stress on students while undergoing online lectures. This shows that the hypotheses of this study are rejected.
\end{abstract}

Keywords: academic stress, emotion regulation strategies, online lectures

Buletin Penelitian Psikologi dan Kesehatan Mental (BRPKM), 2021, Vol. 1(1), 96-103

*Alamat korespondensi: Fakultas Psikologi Universitas Airlangga, Kampus B Universitas Airlangga Jalan Airlangga 4-6 Surabaya 60286. Surel: ika.yuniar@psikologi.unair.ac.id 
sehingga penggunaan, distribusi, reproduksi dalam media apapun atas artikel ini tidak dibatasi, selama sumber aslinya disitir dengan baik.

\section{PENDAH U L U A N}

Sejak akhir tahun 2019, negara-negara di dunia dihebohkan dengan munculnya penyakit baru yang ditemukan di Wuhan, China. Penyakit tersebut kemudian dikenal dengan nama Coronavirus Disease2019 (Covid-19). Covid-19 yang semula merupakan wabah di China, kemudian dinyatakan sebagai pandemi karena persebarannya terus bertambah secara signifikan dalam waktu yang bersamaan dan berkelanjutan di beberapa negara di dunia, termasuk Indonesia (Widyaningrum, 2020). Pada tanggal 30 Januari 2020, WHO secara resmi mengumumkan bahwa Covid-19 menjadi darurat kesehatan global (BBCNews, 2020). Oleh karena itu, berbagai upaya dilakukan untuk mencegah penularan Covid-19. Salah satu upaya terbaik yang dapat dilakukan adalah dengan melakukan pembatasan kontak secara langsung dengan orang lain dan membatasi aktivitas di luar rumah (Mustinda, 2020). Salah satu dampak dari dilakukannya upaya tersebut adalah berubahnya kegiatan perkuliahan. Kementrian Pendidikan dan Kebudayaan Republik Indonesia menetapkan kebijakan untuk melaksanakan pembelajaran dari rumah secara daring selama masa darurat penyebaran Covid-19. Berdasarkan panduan penyelenggaraan pembelajaran yang telah disusun oleh Kemendikbud bersama dengan Kementrian Agama, Kementrian Kesehatan, dan Kementrian Dalam Negeri, tercantum bahwa kegiatan pembelajaran di perguruan tinggi diharapkan agar sebisa mungkin dilaksanakan secara daring, baik untuk mata kuliah teori maupun praktik. Kuliah daring memang merupakan kebijakan yang dirasa paling tepat untuk dilakukan di masa pandemi ini. Namun dalam pelaksanaannya, kuliah daring justru dapat menjadi pemicu timbulnya stres akademis pada mahasiswa.

Penelitian yang dilakukan oleh Son, dkk. (2020) menunjukkan bahwa 82\% mahasiswa memiliki kekhawatiran mengenai performa akademis mereka akibat dari adanya pandemi Covid-19. 38\% mahasiswa merasa bahwa tantangan terbesar yang mereka hadapi adalah transisi pelaksanaan perkuliahan yang berubah menjadi daring. Sejalan dengan hal tersebut, hasil wawancara yang dilakukan terhadap lima mahasiswa Universitas Airlangga menunjukkan bahwa adanya perubahan proses perkuliahan menjadi daring merupakan stresor tersendiri bagi mahasiswa, terutama pada mata kuliah yang memerlukan praktikum. Mahasiswa merasa bahwa mereka menjadi kurang mendapatkan ilmu maupun esensi dari perkuliahan yang mereka jalani. Hal tersebut kemudian mengarah pada munculnya kecemasan mahasiswa terhadap masa depannya. Selain itu, banyaknya tugas yang diberikan selama kuliah daring juga dirasa membebani mahasiswa. Mahasiswa merasa bahwa perkuliahan daring sedikit banyak menghambat mereka dalam mencapai target akademis yang telah mereka tetapkan sebelumnya. Akibat dari adanya stresor tersebut, muncul berbagai reaksi seperti adanya perasaan gelisah, cemas, khawatir, menjadi mudah marah atau tersinggung, mudah menangis, mudah lelah, hingga sering merasa pusing.

Berdasarkan wawancara yang telah dilakukan, gambaran kondisi mahasiswa tersebut sedikit banyak memiliki kesesuaian dengan kondisi stres akademis menurut Gadzella (2004). Stres akademis merupakan stres yang bersumber dari kegiatan pembelajaran atau lingkungan pendidikan. Menurut Gadzella (2004), terdapat lima stresor yang dapat memicu timbulnya stres akademis, yaitu beban diri (self-imposed), adanya perubahan (changes), tekanan (pressures), konflik (conflicts), dan frustrasi. Stres akademis yang dialami mahasiswa juga dapat terjadi karena adanya harapan atau ekspektasi yang tinggi, tuntutan untuk mendapatkan nilai yang baik, banyaknya tugas perkuliahan yang diterima, maupun lingkungan atau proses perkuliahan yang dianggap tidak menyenangkan (Hamaideh, 2011). Hadirnya stresor tersebut kemudian memunculkan reaksi yang berbeda pada setiap individu. Reaksi terhadap stresor dapat berupa reaksi fisiologis, kognitif, emosi, dan tingkah laku (Gadzella, 2004). 
Apabila dibiarkan begitu saja, stres akademis dapat berpengaruh pada performa maupun prestasi mahasiswa yang akan menjadi semakin buruk. Jika hal tersebut terjadi secara terus menerus, maka dapat menyebabkan mahasiswa kehilangan self-esteem, merasa putus asa, atau menganggap dirinya tidak berharga (Lin \& Chen, 2009).

Adanya perubahan dalam pelaksanaan proses perkuliahan selama masa pandemi dan ditambah pula dengan semakin banyaknya tugas pada setiap mata kuliah, rupanya menjadi tekanan tersendiri bagi mahasiswa yang memicu timbulnya stres akademis. Kondisi tersebut apabila dibiarkan begitu saja tentu dapat berpengaruh terhadap performa akademis mahasiswa. Oleh sebab itu, penting bagi mahasiswa untuk memiliki kemampuan regulasi emosi yang baik. Regulasi emosi merupakan suatu proses dimana individu dapat mempengaruhi atau mengatur jenis emosi yang mereka miliki, kapan emosi tersebut muncul, dan juga bagaimana mereka mengalami serta mengekspresikan emosi tersebut (Gross, 2014). Terdapat dua strategi regulasi emosi menurut Gross (2014), yaitu cognitive reappraisal dan expressive suppression. Cognitive reappraisal merupakan strategi regulasi emosi dengan mengubah penilaian atau cara berpikir individu menjadi lebih positif dalam menginterpretasikan suatu kejadian atau kondisi yang dapat menimbulkan emosi. Sedangkan expressive suppression merupakan strategi regulasi emosi dengan cara mengurangi ekspresi emosi yang cenderung berlebihan, baik itu ekspresi wajah, nada suara, maupun perilaku. Penggunaan strategi regulasi emosi yang tepat dalam kehidupan sehari-hari akan berdampak baik terhadap berbagai aspek dalam kehidupan, seperti meningkatkan ketahanan dalam menghadapi kondisi yang menekan hingga berdampak terhadap keberhasilan akademis individu.

Secara umum, regulasi emosi dapat mengurangi tingkat stres akademis pada mahasiswa karena dengan memiliki regulasi emosi yang baik, mahasiswa akan lebih mampu untuk mengekspresikan emosinya secara lebih baik pula. Sejalan dengan hal tersebut, penelitian yang dilakukan oleh Sari, dkk. (2020) menunjukkan bahwa semakin baik regulasi emosi yang dimiliki oleh mahasiswa, semakin rendah pula tingkat stres akademis yang dialaminya karena secara umum regulasi emosi memiliki hubungan dengan penurunan stres akademis. Regulasi emosi secara umum juga dapat dikaitkan dengan peningkatan kesejahteraan psikologis. Namun menurut Troy, dkk. (2013), strategi regulasi emosi, khususnya cognitive reappraisal, akan menjadi adaptif atau maladaptif tergantung pada konteks dimana strategi regulasi emosi tersebut digunakan. Secara khusus, cognitive reappraisal akan menjadi adaptif ketika penyebab stres tidak terkendali, yaitu ketika individu tersebut hanya dapat mengatur dirinya sendiri namun tidak dapat mengubah kondisi di sekitarnya, seperti dalam konteks pandemi ini. Sedangkan ketika stres tersebut dapat dikendalikan oleh individu, yaitu ketika individu tersebut dapat mengubah situasi yang terjadi, terdapat kemungkinan bahwa strategi regulasi emosi justru akan menjadi maladaptif.

\section{Desain Penelitian}

\section{E T ODE}

Tipe penelitian yang digunakan pada penelitian ini adalah kuantitatif. Berdasarkan tujuannya, penelitian ini merupakan penelitian eksplanatori karena bertujuan untuk menguji ada atau tidaknya hubungan antara strategi regulasi emosi dengan stres akademis pada mahasiswa Universitas Airlangga selama menjalani kuliah daring di masa pandemi Covid-19. Penelitian ini ingin menguji hubungan antarvariabel dengan menggunakan teknik survei dimana pengumpulan datanya dilakukan dengan menggunakan kuesioner yang disebarkan secara online melalui media sosial yang dimiliki peneliti. 


\section{Partisipan}

Teknik sampling yang digunakan dalam penelitian ini adalah teknik non-probability sampling dengan menggunakan purposive sampling. Partisipan pada penelitian ini merupakan mahasiswa aktif jenjang sarjana di Universitas Airlangga yang menjalani kuliah daring akibat adanya pandemi Covid-19. Jumlah total partisipan sebanyak 285 orang yang terdiri dari 237 perempuan dan 48 laki-laki. Partisipan berasal dari tiga belas fakultas yang ada di Universitas Airlangga. 34,7\% (99) partisipan berasal dari Fakultas Psikologi, 2,1\% (6) partisipan berasal dari Fakultas Hukum, 6,7\% (19) partisipan berasal dari Fakultas Ilmu Sosial dan Ilmu Politik, 5,6\% (16) partisipan berasal dari Fakultas Kesehatan Masyarakat, 17,9\% (51) partisipan berasal dari Fakultas Ekonomi dan Bisnis, 9,1\% (26) partisipan berasal dari Fakultas Sains dan Teknologi, 9,1\% (16) partisipan berasal dari Fakultas Farmasi, 2,8\% (8) partisipan berasal dari Fakultas Kedokteran Gigi, 1,8\% (5) partisipan berasal dari Fakultas Ilmu Budaya, 1,8\% (5) partisipan berasal dari Fakultas Perikanan dan Kelautan, 2,1\% (6) partisipan berasal dari Fakultas Keperawatan, 3,2\% (9) partisipan berasal dari Fakultas Kedokteran, dan 3,2\% (9) partisipan berasal dari Fakultas Kedokteran Hewan. Sebanyak 49,5\% (141) partisipan merupakan mahasiswa Universitas Airalangga angkatan 2017. 22,5\% (64) partisipan berasal dari angkatan 2018, 15,4\% (44) partisipan berasal dari angkatan 2019, dan 12,6\% (36) partisipan berasal dari angkatan 2020.

\section{Pengukuran}

Alat ukur yang digunakan untuk mengukur strategi regulasi emosi adalah Emotion Regulation Questionnaire (ERQ) milik Gross dan John (2003) yang telah diadaptasi oleh Pratiwi (2019). Terdapat 10 aitem dalam Emotion Regulation Questionnaire yang terdiri dari 6 aitem cognitive reappraisal dan 4 aitem expressive suppression. Emotion Regulation Questionnaire (ERQ) yang diadaptasi oleh Pratiwi (2019) memiliki reliabilitas sebesar 0,756 untuk cognitive reappraisal dan 0,744 untuk expressive suppression. Variasi jawaban pada Emotion Regulation Questionnaire adalah sangat setuju, setuju, cukup setuju, netral, agak tidak setuju, tidak setuju, dan sangat tidak setuju. Semakin tinggi skor cognitive reappraisal dibandingkan dengan skor expressive suppression, maka individu lebih dominan menggunakan regulasi emosi cognitive reappraisal. Begitu juga sebaliknya, semakin tinggi skor expressive suppression dibandingkan dengan skor cognitive reappraisal, maka individu lebih dominan menggunakan regulasi emosi expressive suppression.

Alat ukur yang digunakan untuk mengukur stres akademis adalah Student-life Stress Inventory (SSI) dari Gadzella (1994) yang telah diadaptasi oleh Sarina (2012). Terdapat 51 aitem dalam Student-life Stress Inventory yang terdiri dari 23 aitem mengenai stresor akademis dan 28 aitem mengenai reaksi terhadap stresor. Student-life Stress Inventory yang diadaptasi oleh Sarina (2012) memiliki reliabilitas sebesar 0,906. Variasi jawaban pada alat ukur Student-life Stress Inventory yaitu tidak pernah, jarang, kadangkadang, sering, dan hampir setiap waktu. Skor tinggi yang didapatkan oleh individu pada alat ukur ini menunjukkan bahwa ia memiliki stres akademis yang berat. Begitu juga sebaliknya, individu dengan skor yang rendah menunjukkan bahwa ia memiliki stres akademis yang ringan. Terdapat norma yang digunakan dalam skala stres akademis yang terdiri atas tiga kelompok, yaitu mild dengan rentang skor 51-119, moderate dengan rentang skor 120-145, dan severe dengan skor lebih dari 145 (Sarina, 2012).

\section{Analisis Data}

Analisis data akan dilakukan menggunakan program IBM SPSS Statistic 22.0 for Windows. Uji asumsi yang dilakukan terhadap data adalah uji normalitas dan uji linearitas. Setelah itu, dilakukan uji korelasi dengan menggunakan Product Moment Pearson untuk mengetahui apakah hipotesis penelitian ini diterima atau ditolak. 


\section{HAS IL P E N ELIT IAN}

Berdasarkan hasil analisis statistik deskriptif, diketahui pada variabel cognitive reappraisal $M=32,54$; $S D=5,721$ dan pada variabel expressive suppression $M=18,4561 ; S D=4,96071$. Sedangkan pada variabel stres akademis $M=155,46 ; S D=26,316$. Peneliti melakukan kategorisasi atau penormaan pada variabel stres akademis. Hasilnya, 188 partisipan berada pada tingkat stres akademis severe. Sedangkan 75 partisipan berada pada tingkat stres akademis moderate dan 22 partisipan berada pada tingkat stres akademis mild.

Penelitian ini menggunakan teknik statistik parametrik dengan Product Moment Pearson untuk melakukan uji korelasi. Berdasarkan uji korelasi yang telah dilakukan, diketahui bahwa terdapat hubungan yang cenderung lemah dan positif antara cognitive reappraisal dengan stres akademis $(r(285)=0,042)$. Selain itu, terdapat juga hubungan yang cenderung lemah dan positif antara dengan stres akademis $(r(285)=0,068)$. Diketahui pula bahwa $p=0,477$ untuk cognitive reappraisal dengan stres akademis dan $p=0,249$ untuk expressive suppression dengan stres akademis. Variabel dapat dikatakan saling berhubungan apabila nilai signifikansinya kurang dari 0,05 (Pallant, 2011). Sehingga dapat disimpulkan bahwa tidak terdapat hubungan yang signifikan antara strategi regulasi emosi dengan stres akademis pada mahasiswa Universitas Airlangga selama menjalani kuliah daring di masa pandemi Covid-19. Hal tersebut menunjukkan bahwa kedua hipotesis penelitian ini ditolak.

\section{I S K U S I}

Penelitian ini bertujuan untuk mengetahui hubungan strategi regulasi emosi yang terdiri dari cognitive reappraisal dan expressive suppression dengan stres akademis pada mahasiswa Universitas Airlangga selama menjalani kuliah daring di masa pandemi Covid-19. Hasil dari analisis statistik pada penelitian ini menunjukkan bahwa hipotesis penelitian ditolak, yang berarti bahwa tidak terdapat hubungan yang signifikan antara cognitive reappraisal maupun expressive suppression dengan stres akademis pada pada mahasiswa Universitas Airlangga selama menjalani kuliah daring di masa pandemi Covid-19. Hasil analisis pada penelitian ini berbeda dengan penelitian-penelitian sebelumnya, dimana pada penelitianpenelitian sebelumnya mengatakan bahwa secara umum terdapat hubungan yang signifikan antara strategi regulasi emosi dengan stres akademis.

Hipotesis yang ditolak dimungkinkan karena adanya faktor lain yang jauh lebih dominan terhadap stres akademis, terutama pada kondisi pandemi seperti sekarang ini. Seperti pada penelitian yang dilakukan oleh Son, dkk. (2020) mengenai akibat dari pandemi Covid-19 terhadap kesehatan mental mahasiswa di Amerika serikat, diperoleh informasi mahasiswa memerlukan dukungan dari orang lain dalam mengatasi stres yang dialaminya. Sebanyak 34\% responden penelitian menyebutkan bahwa berkomunikasi dengan keluarga atau teman merupakan cara utama untuk mengatasi stres, termasuk stres akademis, yang terjadi selama pandemi Covid-19. Sejalan dengan hal tersebut, Marhamah dan Hamzah (2016) menyebutkan bahwa mahasiswa dengan level dukungan sosial yang tinggi, memiliki level stres akademis yang lebih rendah.

Selain itu, menurut Salovey \& Sluyter (1997), dibandingkan dengan laki-laki, perempuan cenderung lebih banyak mencari dukungan maupun perlindungan dari orang lain dalam mengelola emosi negatif yang mereka alami. Jika dilihat dari jumlah responden pada penelitian ini, dimana responden perempuan berjumlah 237 dan responden laki-laki berjumlah 48, hal tersebut dirasa dapat mendukung ditolaknya hipotesis penelitian ini. Kemudian jika dilihat kembali pada wawancara yang dilakukan oleh peneliti, dapat diketahui bahwa dukungan dari orang-orang di sekitar dapat membuat mahasiswa

Buletin Riset Psikologi dan Kesehatan Mental (BRPKM) 2021, Vol. 1(1), 96-103 
merasa lebih baik dalam menghadapi kondisi yang menekan. Ketika perkuliahan dilakukan secara langsung, mahasiswa dapat lebih leluasa untuk saling berbagi keluh kesah. Berbeda dengan ketika pandemi dimana mahasiswa merasa bahwa ia harus menanggung semuanya seorang diri. Maka dari itu kehadiran teman dirasa sangat penting bagi mahasiswa. Selain itu, dukungan dari orang tua juga dapat membantu mahasiswa dalam menghadapi kondisi yang menekan ketika menjalani perkuliahan daring di rumah.

Strategi regulasi emosi, jika dilihat berdasarkan metode coping menurut Lazarus dan Folkman (1984), termasuk ke dalam emotion-focused coping. Emotion-focused coping adalah cara penanggulangan stres dengan melibatkan emosi. Individu yang mengalami stres akan melibatkan emosinya dan menggunakan penilainnya terhadap sumber-sumber stres yang ada. Bagi mahasiswa yang mengalami stres akademis, strategi regulasi emosi mungkin memang membantu untuk mereduksi emosi negatif yang ia rasakan, namun tidak mampu membantu untuk menyelesaikan permasalahan yang mereka hadapi. Sehingga stres akademis yang mereka alami tidak benar-benar teratasi karena dapat muncul lagi di kemudian hari. Meskipun pada umumnya strategi regulasi emosi, baik cognitive reappraisal maupun expressive suppression, dapat digunakan untuk mereduksi stres yang dialami oleh individu, namun expressive suppression secara konsisten dapat memperburuk kondisi individu tersebut (Gross, 2014). Penekanan emosi negatif yang dilakukan secara terus-menerus justru dapat meningkatkan stres pada individu (Patel \& Patel, 2019). Selain itu, berdasarkan penelitian yang dilakukan oleh Denson, dkk. (2014), diketahui bahwa cognitive reappraisal dalam jangka pendek dapat meningkatkan reaktivitas kortisol. Kortisol merupakan hormon yang berkaitan dengan respons tubuh terhadap stres. Hormon kortisol dihasilkan oleh kelenjar adrenal dan dilepaskan ketika individu menghadapi stres, sehingga sering juga disebut sebagai indikator stres. Ketika individu mengalami stres, maka hormon kortisol akan meningkat. Kadar hormon kortisol yang terlalu tinggi karena merespons stres dapat berbahaya bagi kondisi tubuh individu. Berdasarkan penelitian Denson, dkk. (2014) juga dijelaskan bahwa hasil penelitian tersebut konsisten dengan hasil penelitian-penelitian sebelumnya yang menyebutkan bahwa cognitive reappraisal dapat meningkatkan reaktivitas fisiologis di bawah tekanan seperti sumbu hipotalamus pituitary adrenal (HPA).

\section{S I M P U L A N}

Hasil analisis pada penelitian ini menunjukkan bahwa hipotesis penelitian ditolak, yang berarti bahwa tidak terdapat hubungan yang signifikan antara cognitive reappraisal maupun expressive suppression dengan stres akademis pada pada mahasiswa Universitas Airlangga selama menjalani kuliah daring di masa pandemi Covid-19. Saran untuk penelitian selanjutnya adalah dapat memberikan kajian mengenai strategi regulasi emosi dengan variabel lain ataupun stres akademis dengan variabel lain. Apabila penelitian selanjutnya ingin menggunakan populasi yang sama seperti penelitian ini, perlu diperhatikan jumlah partisipan di setiap fakultasnya agar selisih partisipan tidak berbeda jauh. Saran untuk keluarga, teman, maupun dosen adalah agar secara aktif memantau kondisi atau keadaan mahasiswa, contohnya dengan menanyakan kabar. Orang tua dapat lebih memahami bahwa saat ini anak berada di rumah bukan untuk liburan, masih ada tanggung jawab lain yang harus dilakukan, yaitu kuliah. Teman diharapkan untuk saling mendukung dalam menjalani perkuliahan di masa pandemi ini dan saling berbagi keluh kesah sehingga tidak merasa sendiri dalam menghadapi kondisi ini. Dosen dapat melakukan evaluasi proses pembelajaran secara berkala dan memfasilitasi mahasiswa untuk mendiskusikan kesulitan atau hambatan yang dihadapi selama menjalani kuliah daring. 


\section{U C A P A N T ER I MAKASIH}

Penulis berterima kasih kepada seluruh responden dalam penelitian ini sehingga penelitian dapat terselesaikan dengan baik.

\section{DEKLARASI POTENSI TERJADINYA KONFLIK KEPENTINGAN}

Arini Rachmawati dan Ika Yuniar Cahyani tidak bekerja, menjadi konsultan, memiliki saham, atau menerima dana dari perusahaan atau organisasi manapun yang mungkin akan mengambil untung dari diterbitkannya naskah ini.

\section{PUSTAKA ACUAN}

BBCNews. (2020, Juni 9). Covid-19: Kajian kasus di Wuhan muncul sejak akhir Agustus, China sebut hasil itu 'sebagai hal yang konyol'. Retrieved September 1, 2020, from BBC News Indonesia: https://www.bbc.com/indonesia/dunia-52977852

Denson, T. F., Creswell, J. D., Terides, M. D., \& Blundell, K. (2014). Cognitive reappraisal increases neuroendocrine reactivity to acute social stress and physical pain. Psychoneuroendocrinology, 69-78.

Field, A. (2009). Discovering statistics using SPSS (3rd ed.). London: SAGE Publications Ltd.

Gadzella, B. (1994). Student-life stress inventory: Identification of and reactions to stressors. Psychological Reports, 395-402.

Gadzella, B. (2004). Three stress groups on their stressors and reactions to stressors in five studies. Psychological Reports, 562-564.

Gross, J. (2014). Emotion regulation: Conceptual and empirical foundations. In J. J. Gross, Handbook of Emotion Regulation Second Edition (pp. 3-20). New York: The Guilford.

Gross, J., \& John, O. (2003). Individual differences in two emotion regulation processes: implications for affect, relationships, and well-being. Journal of Personality and Social Psychology, 348-362.

Hamaideh, S. H. (2011). Stressors and reactions to stressors among university students. International Journal of Social Psychiatry, 69-80.

Lazarus, R. S., \& Folkman, S. (1984). Stress, appraisal, and coping. New York: Springer Publishing Company.

Lin, Y. M., \& Chen, F. S. (2009). Academic stress inventory of students at universities and colleges of technology. World Transactions on Engineering and Technology Education, 157-162.

Marhamah, F., \& Hamzah, H. (2016). The relationship between social support and academic stress among first year students at syiah kuala university. Jurnal Psikoislamedia, 149-172. 
Mustinda, L. (2020, April 7). Perbedaan Social Distancing, Physical Distancing hingga PSBB. Retrieved September 1, 2020, from detikNews: https://news.detik.com/berita/d-4968496/perbedaansocial-distancing-physical-distancing-hingga-psbb

Pallant, J. (2011). SPSS survival manual: a step by step guide to data analysist using SPSS (4th ed.). Crows Nest: ALLEN \& UNWIN.

Patel, J., \& Patel, P. (2019). Consequences of repression of emotion: Physical health, mental health and general well being. International Journal of Psychotherapy Practice and Research, 16-21.

Pratiwi, H. (2019). Perbedaan tingkat kepuasan perkawinan ditinjau dari strategi regulasi emosi pada wanita dewasa awal di lima tahun pertama perkawinan. Skripsi. Surabaya: Universitas Airlangga.

Salovey, P., \& Sluyter, D. J. (1997). Emotional Development and Emotional Intelligence: Educational Implications. New York: Basic Books.

Sari, P., Bulantika, S. Z., Dewantari, T., \& Rimonda, R. (2020). Effects of Stress Coping and Emotion Regulation on Student Academic Stress. KONSELI: Jurnal Bimbingan dan Konseling (E-Journal), 73-80.

Sarina, N. (2012). Hubungan antara stres akademis dan psychological well being pada mahasiswa tahun pertama. Skripsi. Jakarta: Universitas Indonesia.

Son, C., Hegde, S., Smith, A., Wang, X., \& Sasangohar, F. (2020). Effects of COVID-19 on college students' mental health in the United States: Interview survey study. Interview survey study. Journal of medical internet research.

Troy, A. S., Shallcross, A. J., \& Mauss, I. B. (2013). A person-by-situtation approach to emotion regulation: Cognitive reappraisal can either help or hurt, depending on the contect. Psychological Science, 110.

Widyaningrum, G. L. (2020, Maret 12). WHO Tetapkan Covid-19 sebagai Pandemi Global, Apa Maksudnya? Retrieved September 1, 2020, from National Geographic Indonesia: https://nationalgeographic.grid.id/read/132059249/who-tetapkan-covid-19-sebagaipandemi-global-apa-maksudnya 